\title{
Soluble Receptor for Advanced Glycation End Products and Its Correlation with Vascular Damage in Adolescents with Obesity
}

\author{
Reyna Rodríguez-Mortera ${ }^{a}$ Claudia Luevano-Contreras ${ }^{a}$ \\ Sergio Solorio-Meza ${ }^{b}$ Armando Gómez-Ojeda ${ }^{a}$ Russell Caccavelloc \\ Yasmin Bains $^{c}$ Alejandro Gugliuccic Ma. Eugenia Garay-Sevilla ${ }^{c}$ \\ ${ }^{a}$ Department of Medical Science, University of Guanajuato, León, Mexico; b Mexican Institute of Social Security, \\ León, Mexico; ' Department of Research, Glycation, Oxidation and Disease Laboratory, College of Osteopathic \\ Medicine, Touro University, Vallejo, CA, USA
}

\section{Keywords}

Advanced glycation end products · Soluble receptor for advanced glycation end products · Obesity · Vascular damage

\begin{abstract}
Objective: The aim of this study was to evaluate soluble receptor for advanced glycation end products (sRAGE) and advanced glycation end products (AGEs) in adolescents with and without obesity $(\mathrm{OB})$ and their correlation with vascular damage. Methods: This is a cross-sectional study with 15-19 years old adolescents: 33 with $\mathrm{OB}$ and 33 with normal weight (NW), each group included 17 male and 16 female. Lipid profile, insulin, carboxymethylysine (CML), sRAGE, total AGEs, and dietary AGEs intake (dAGEs) were evaluated. Vascular damage was measured by flow-mediated vasodilation (FMD) and arterial stiffness index $(I \beta)$. Homeostatic model assessment-insulin (HOMA-IR) and atherogenic index (AI) were calculated. Results: The group with $\mathrm{OB}$ had higher triglycerides (TG; $p<0.0001), \mathrm{Al}(p<0.001)$, HOMA-IR $(p<0.0001)$, dAGEs intake $(p<0.0001)$, lower CML $(p=0.05)$, total AGEs $(p<0.01)$, sRAGE $(p<0.001)$, and FMD $(p<0.002)$. In the total group, sRAGE correlated with AI $(r=-0.26 p=0.037)$; in the NW
\end{abstract}

\section{KARGER}

() 2019 S. Karger AG, Basel

E-Mail karger@karger.com

www.karger.com/hrp group, CML correlated with I $\beta(r=-0.36 ; p=0.037)$; and in the group of adolescents with OB, sRAGE correlated with $\operatorname{FMD}(r=-0.37 ; p=0.037)$ and $\mathrm{I} \beta(r=0.47 ; p=0.006)$, while $\mathrm{CML}$ and total AGEs correlated with $\mathrm{Al}, p=0.007$ and $p<0.01$, respectively). Conclusions: The group of adolescents with $O B$ showed higher cardiometabolic risk as shown by higher TG, Al, HOMA-IR, and lower sRAGE and FMD. sRAGE correlated negatively with FMD and positively with $I \beta$, so it could be suggested as a biochemical marker of impaired endothelial function.

(c) 2019 S. Karger AG, Basel

\section{Introduction}

Obesity $(\mathrm{OB})$ is one of the major causes of cardiovascular disease morbidity and mortality, and its prevalence has rapidly increased worldwide [1]. The pathological processes and risk factors associated with atherosclerosis, including vascular endothelial dysfunction, begin during childhood and adolescence [2].

Arterial stiffness [3] and flow-mediated vasodilation (FMD) [4] are considered as an early clinical indicator of vascular damage. Greater arterial stiffness has been report- 
ed in children with $\mathrm{OB}$ at the carotid artery $[5,6]$, and it has also been reported lower arterial stiffness measurement in children with $\mathrm{OB}$ with a possible cardiometabolic dysfunction [7]. In adolescents with no additional metabolic or clinical risk factors, FMD may be useful in identifying these children with early signs of atherosclerotic development [8]. Adolescents with OB have shown higher atherogenic index (AI), a measurement used to predict cardiovascular risk [9]. Among the factors that could play a role in atherogenesis, the advanced glycation end products (AGEs)/receptor for advanced glycation end products (RAGE) axis has been shown to play an important role in the development of cardiovascular diseases [10]. AGEs can be formed endogenously as a consequence of metabolism, and they can be ingested through food (dietary AGEs [dAGEs]) [11]. AGEs could increase vascular and myocardial stiffening and could stimulate inflammation and oxidative stress through the RAGE [12]. RAGE has a C-truncated secreted isoform, called soluble RAGE (sRAGE). AGEs also bind to sRAGE, and it has been proposed that sRAGE interacts competitively with RAGE as a decoy for AGEs, preventing hyperactivation of RAGE and its dire inflammatory consequences [13]. However, studies on sRAGE concentrations in cardiovascular disease are contradictory in adults [14, 15]. There has been a paucity of research on the subject conducted in younger populations. Studies on prepubertal children showed that $\mathrm{OB}$ is associated with low levels of sRAGE $[16,17]$ and suggest that these pathways in the process of atherosclerosis begin during adolescence or even earlier [18]. We carried out this study to evaluate sRAGE and AGEs in adolescents with and without $\mathrm{OB}$ and its correlation with vascular damage. To the best of our knowledge, the present study is the first to assess the levels of AGE/RAGE axis and markers of vascular damage such as FMD and arterial stiffness in adolescents.

\section{Material and Methods}

\section{Subjects}

This is a cross-sectional study of 66 adolescents: 33 with $\mathrm{OB}$ and 33 with normal weight (NW). They were recruited between October 2015 and July 2016 from schools in the city of Leon, Mexico. Anthropometric evaluations were performed following standardized methods, and the groups were classified based on their body mass index (BMI) according to Cole et al. [19] tables. Participants were male and female between 15 and 19 years old, with stage IV or $\mathrm{V}$ of Tanner scale, with no history of chronic diseases, tobacco smoking, and no evidence of any acute infection. This study was approved by the institutional Ethical Committee at the University of Guanajuato (CIBIUG-P-28-2015). Both adolescents and their parents or tutors signed an informed consent form.

\section{Data Collection}

The evaluation of blood pressure (BP) was according to the National High Blood Pressure Education Program, and noninvasive endothelial function assessment was performed following standardized methods [20,21].

A venous blood sample was obtained after $12 \mathrm{~h}$ of fasting, and serumwasprocessed the samedayto measureglucose (GOD-PAP ${ }^{\mathrm{TM}}$, Lakeside, Mexico City) lipids by enzymatic methods (Spinreact, Spain). AI was calculated as (total cholesterol/high density lipoprotein-cholesterol [HDL-C]). Serum aliquots were stored at $-80^{\circ} \mathrm{C}$ until further analyses. Insulin was measured by ELISA $\left(\mathrm{ALPCO}^{\mathrm{TM}}\right.$, Salem, NH, USA), and homeostatic model assessment-insulin (HOMA-IR) was defined as above 95\% percentile, according to a previous report in Mexican adolescents [22].

\section{AGE-sRAGE Determinations}

sRAGE levels were determined using a commercial ELISA kit (Quantikine ELISA kit; R\&D Systems, Minneapolis, MN, USA). Carboxymethylysine (CML) was measured in serum by an ELISA, using non-cross-reactive monoclonal antibodies (4G9) raised against a synthetic standard, CML-BSA (donated by the group of Mount Sinai, New York, NY, USA) [23]. The total AGEs in serum were measured by fluorescence, using a Biotek Synergy H1, and top fluorescence was recorded at Excitation: $\lambda 370 \mathrm{~nm}$, Emission: $\lambda 440 \mathrm{~nm}$ against blanks and expressed in AU [24].

\section{Dietary Intake}

Energy, macronutrients, and dAGEs intake were estimated from 3-day 24-h recalls (1 day of the weekend and 2 days of the week). The content of daily dAGEs was estimated with a food database with the AGE content [11]; dAGEs were expressed in kilounits (KU). Nutrients and energy were estimated with the software Food Processor $\left(2015^{\circledR}\right)$.

\section{Vascular Damage Assessment}

Brachial artery FMD was measured with the aid of a pneumatic cuff which was placed on the forearm and was inflated to above systolic pressure for $5 \mathrm{~min}$ to induce ischemia. On deflation of the cuff, the increased flow results in stress. The stress activates endothelial nitric oxide synthase to release nitric oxide which diffuses into the smooth muscle cells causing relaxation and vasodilation. The ultrasound images of the brachial artery were obtained at baseline and after the release of the cuff. The percentage change in brachial artery diameter from baseline to the maximum increase in diameter represents FMD, and an increase $<10 \%$ in the diameter of the artery suggests the presence of arterial disease [20].

Arterial stiffness index (I $\beta)$. Stiffness index was calculated according to Mackenzie's formula: stiffness index $=$ ratio of $\ln$ (systolic/diastolic pressures) to (relative change in artery diameter $) ; \mathrm{I} \beta=(\ln [\mathrm{Ps} / \mathrm{Pd}]) /([\mathrm{Ds}-\mathrm{Dd}] / \mathrm{Dd})(\mathrm{P}$, pressure; $\mathrm{D}$, artery diameter; s, systolic; d, diastolic) [21]. The ultrasound assessments were made using a ACUSON X150 ${ }^{\mathrm{TM}}$ 2-dimensional ultrasound machine (Siemens, Mexico City, Mexico).

AI was calculated as (total cholesterol/HDL-C).

\section{Statistical Analysis}

Results are expressed as mean \pm SD for continuous variables and as the median and interquartile range for variables with a skewed distribution. Differences between groups were evaluated by the student $t$ test or Mann-Whitney U test. Pearson's correla- 
Table 1. Clinic and metabolic characteristics of adolescents

\begin{tabular}{|c|c|c|c|}
\hline Variables & OB $(n=33)$ & $\mathrm{NW}(n=33)$ & $p$ value \\
\hline Age, years & $16.94 \pm 1.32$ & $16.63 \pm 1.51$ & 0.44 \\
\hline Gender, female/male, $n$ & $17 / 16$ & $17 / 16$ & - \\
\hline Systolic BP, mm Hg & $116.09 \pm 7.38$ & $108.97 \pm 8.49$ & $<0.001$ \\
\hline Diastolic BP, mm Hg & $72.79 \pm 6.77$ & $68.60 \pm 6.83$ & 0.02 \\
\hline \multicolumn{4}{|l|}{ Anthropometric measurements } \\
\hline Weight, kg & $89.46 \pm 14.23$ & $57.14 \pm 8.18$ & $<0.0001$ \\
\hline Height, cm & $164.87 \pm 8.70$ & $162.62 \pm 7.44$ & 0.26 \\
\hline BMI, $\mathrm{kg} / \mathrm{m}^{2}$ & $32.77 \pm 3.89$ & $21.58 \pm 2.26$ & $<0.0001$ \\
\hline Waist circumference & $98.50 \pm 9.50$ & $72.50 \pm 5.33$ & $<0.0001$ \\
\hline \multicolumn{4}{|l|}{ Lipid and glucose metabolism } \\
\hline $\mathrm{TC}, \mathrm{mmol} / \mathrm{L}$ & $4.33 \pm 0.95$ & $3.96 \pm 0.76$ & 0.08 \\
\hline HDL-C, mmol/L & $1.50 \pm 0.26$ & $1.64 \pm 0.13$ & $<0.007$ \\
\hline $\mathrm{TG}^{*}, \mathrm{mmol} / \mathrm{L}$ & $1.48(1.14-1.68)$ & $0.85(0.62-1.16)$ & $<0.0001$ \\
\hline AI & $2.95 \pm 0.67$ & $2.43 \pm 0.48$ & $<0.001$ \\
\hline Glucose, $\mathrm{mmol} / \mathrm{L}$ & $5.04 \pm 0.59$ & $4.94 \pm 0.54$ & 0.49 \\
\hline Insulin, $\mu \mathrm{IU} / \mathrm{mL}^{\mathrm{a}}$ & $15.64(11.11-23.25)$ & $7.78(6.48-10.14)$ & $<0.0001$ \\
\hline HOMA-IR & $3.30(2.54-5.33)$ & $1.78(1.31-2.20)$ & $<0.0001$ \\
\hline \multicolumn{4}{|l|}{ Diet } \\
\hline Kcal/day & $2,548.59 \pm 713.98$ & $2,240.33 \pm 752.24$ & 0.09 \\
\hline Protein, g/day & $95.70 \pm 27.18$ & $91.35 \pm 27.18$ & 0.53 \\
\hline Lipids, g/day & $98.54 \pm 31.14$ & $86.67 \pm 27.18$ & 0.13 \\
\hline Carbohydrates, g/day & $324.83 \pm 105.17$ & $279.43 \pm 108.03$ & 0.09 \\
\hline dAGEs (KU)/day & $14,577.03 \pm 5,492.12$ & $8,525.67 \pm 3,309.93$ & $<0.0001$ \\
\hline \multicolumn{4}{|l|}{ AGE/RAGE axis } \\
\hline $\mathrm{CML}, \mu \mathrm{g} / \mathrm{mL}$ & $1.49 \pm 1.16$ & $1.99 \pm 0.87$ & 0.05 \\
\hline sRAGE, pg/mL & $1,306.10 \pm 505.75$ & $1,800.04 \pm 605.94$ & 0.0006 \\
\hline Total AGEs F (AU) ${ }^{a}$ & $1,256.75(1,092.50-1,469.75)$ & $1,424(1,304.00-1,620.50)$ & 0.008 \\
\hline \multicolumn{4}{|l|}{ Vascular damage } \\
\hline FMD & $20.70 \pm 6.77$ & $27.19 \pm 9.83$ & 0.003 \\
\hline Arterial stiffness index (I $\beta)$ & $2.84 \pm 2.59$ & $1.98 \pm 0.94$ & 0.08 \\
\hline
\end{tabular}

a Mann-Whitney U test for nonparametric variables. Data are shown as mean \pm SD for normally distributed variables or as median and interquartile range for non-Gaussian variables. BP, blood pressure; BMI, body mass index; HOMA-IR, homeostatic model assessment-insulin; CML, carboxymethyl-lysine; sRAGE, soluble receptor for advanced glycation end products; total AGEs F, total advanced glycation end products by fluorescence; FMD, flow-mediated vasodilation; AI, atherogenic index; TC/HDL-C, total cholesterol/high-density lipoproteincholesterol; dAGEs, dietary AGEs; OB, obesity; NW, normal weight.

tion analysis was used to determine the univariate correlation between the different variables in the study and the Spearman correlation for nonparametric variables. All analyses were performed using Statistica 7 software (StatSoft Inc., Tulsa, OK, USA). Significance was defined as a value of $p<0.05$.

\section{Results}

The clinical and biochemical characteristics of both groups according to BMI are shown in Table 1. Both systolic and diastolic BPs were significantly higher in adolescents with $\mathrm{OB}$ and showed significantly higher triglycer- ides (TG; $p<0.0001)$, AI $(p<0.001)$, HOMA-IR $(p<$ $0.0001)$, and dAGEs $(<0.0001)$. In contrast, HDL-C $(p<$ $0.007)$, sRAGE $(p<0.0006)$, and total AGEs $(p<0.008)$ were lower than in the group with NW. FMD was significantly lower in the group with $\mathrm{OB}(p<0.003)$, while arterial stiffness index was higher in this group with a marginal $p$ value $(p<0.08)$.

The main outcome variables were analyzed by gender. Males showed significantly higher levels of sRAGE $(1,772.7 \pm 644.6$ vs. $1,346.4 \pm 494.9 \mathrm{pg} / \mathrm{mL} p<0.0003)$ and total AGEs (AU) 1,423 (1,310.5-1,548.0) versus 1,213 $(1,080.00-1,500.50)$, when compared to females. No significant differences were found for other variables, and 
Table 2. Correlations between AGE/RAGE axis and markers of vascular damage in the group with OB

\begin{tabular}{|c|c|c|c|c|c|c|}
\hline \multirow{3}{*}{$\begin{array}{l}\text { AGE/RAGE } \\
\text { axis }\end{array}$} & \multicolumn{6}{|c|}{ Vascular damage } \\
\hline & \multicolumn{2}{|l|}{ FMD } & \multicolumn{2}{|c|}{ arterial stiffness $(\mathrm{I} \beta)$} & \multicolumn{2}{|l|}{ AI } \\
\hline & $r$ & $p$ value & $r$ & $p$ value & $r$ & $p$ value \\
\hline CML & -0.05 & 0.80 & 0.16 & 0.39 & 0.46 & 0.007 \\
\hline Total AGEs F & 0.18 & 0.48 & 0.14 & 0.48 & 0.47 & $<0.01$ \\
\hline sRAGE & -0.37 & 0.037 & 0.47 & 0.006 & 0.05 & 0.76 \\
\hline
\end{tabular}

AGE/RAGE, advanced glycation end products/receptor for advanced glycation end products; FMD, flowmediated vasodilation; AI, atherogenic index; CML, carboxymethyl-lysine; sRAGE, soluble receptor for advanced glycation end products; total AGEs F, total advanced glycation end products by fluorescence.

no significant differences were found according to the Tanner stage.

Regarding AGE/RAGE axis, only a negative correlation between sRAGE and CML $(r=-0.35, p=0.044)$ was found in the NW group. In addition, a negative correlation between sRAGE and AI $(r=-0.26 ; p=0.037)$ in the total group and between CML and arterial stiffness $(r=$ $-0.36 ; p=0.037)$ in the NW group were found.

In the group with OB (Table 2), CML and total AGEs correlated significantly with AI (Fig. $1 ; p=0.007$ and $p<$ 0.01 , respectively). sRAGE correlated negatively with FMD $(p=0.037)$ and positively with arterial stiffness $(p=$ 0.006; Fig. 2). These correlations were maintained after adjusting for BMI and insulin.

\section{Discussion}

In this study, we show that serum CML, total AGEs, and sRAGE are lower, while dAGEs consumption are higher in adolescents with $\mathrm{OB}$ compared to subjects with NW and that sRAGE is negatively associated with FMD and positively associated with arterial stiffness. Moreover, we also show that structural vascular damage (measured by arterial stiffness) and impaired endothelial function (FMD) are already present in adolescents with $\mathrm{OB}$ and associate in part with the AGE/RAGE axis.

Regarding the AGE/RAGE axis, our results are in agreement with those reported by Sebeková et al. [25] who found significantly lower levels of CML and AGEassociated fluorescence in children/adolescents with $\mathrm{OB}$ compared with their counterparts with NW and with another study that showed lower CML with adiposity [26]. A previous study in our groups with metabolically healthy adolescents did not show significant differences in serum CML [27]. On the other hand, our results are in contrast with the assumption that $\mathrm{OB}$ is related to enhance oxidative stress and micro-inflammation, and this would be reflected by higher plasma AGE levels [26]. The most plausible explanation lies in the nature of the compounds measured. The most important MGderived AGE is MG hydroimidazolone-1, and this has not been measured in previous studies in obese children nor in ours. Additionally, lower levels of CML and total AGEs have been explained due to enlargement of adipose tissue mass in OB [28]. A contributory feature of this is a likely decreased glycation of albumin due to the shift of albumin from plasma to interstitial fluid. An association with inflammation is also expected as transcapillary albumin escape rate increases with increased capillary permeability in vascular inflammation [28, 29].

A study in adults showed that fat mass is inversely associated with serum CML suggesting that serum CML concentration is strongly affected by body fat. This association could be explained by the fact that CML is preferentially deposited in fat tissue or because adipocytes affect the metabolism of AGE [30]. In that sense, circulating CML does not reflect total body content of CML and notably the flux, which may well be increased. The increased flow of AGEs is partially quenched by sRAGE, which could then reduce their steady-state concentration. Sustained engagement of RAGE decreases glyoxalase 1 activity, the main detoxifier of $\mathrm{MG}$, creating another vicious cycle [31].

Regarding dAGEs intake, there is only one study where dAGEs consumption was evaluated in adolescents; Saha et al. [32] reported that higher consumption of dAGEs is associated with an increase in the odds to have the metabolic syndrome components, specifically waist circum- 


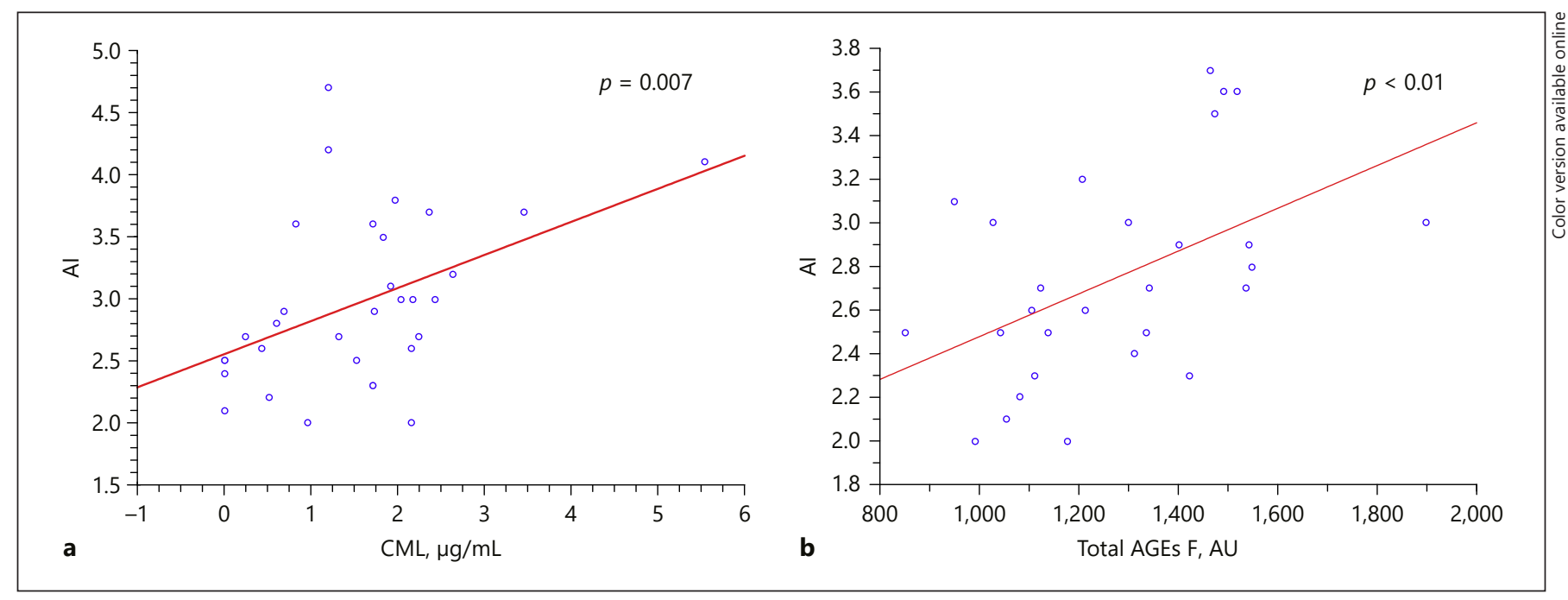

Fig. 1. Correlations in the OB group. The figure shows the correlations find between AI with CML (a) and with total AGEs (b). AI, atherogenic index; CML, carboxymethylysine; AGEs, advanced glycation end.

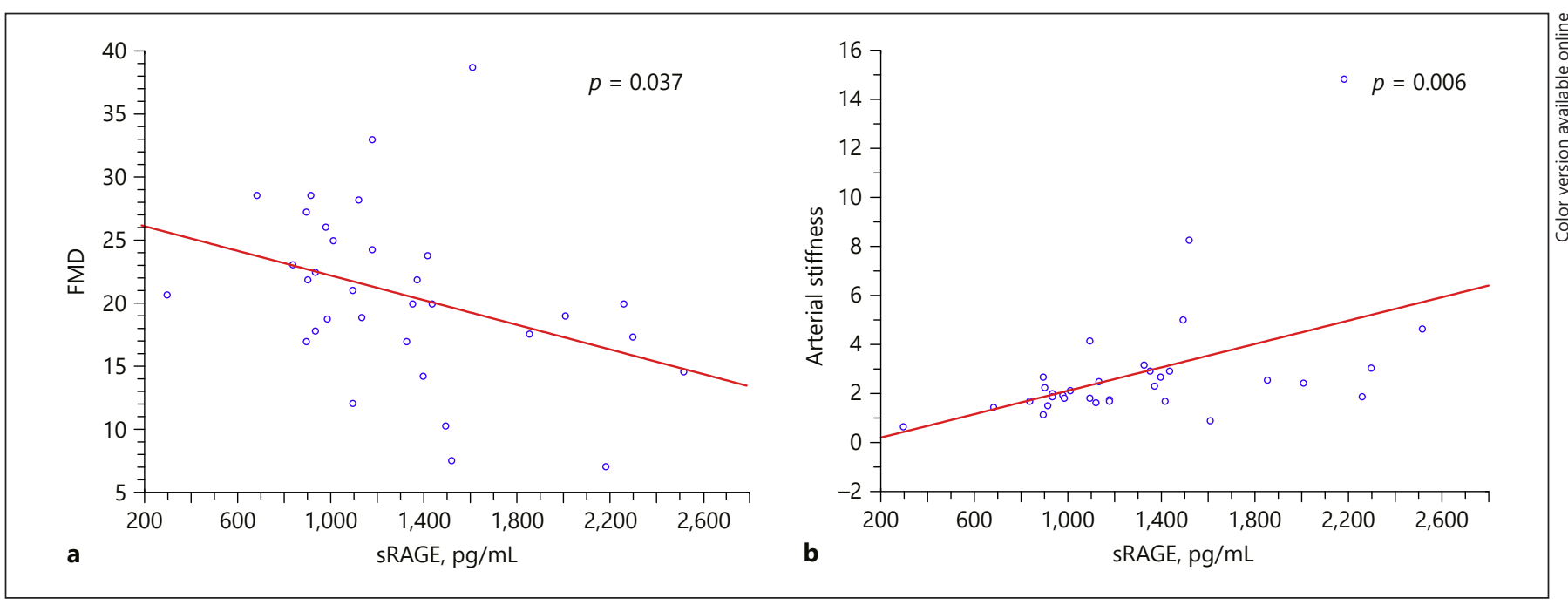

Fig. 2. Correlations in the OB group. The figure shows the correlations find between sRAGE with FMD (a) and with arterial stiffness (b). FMD, flow-mediated vasodilation; sRAGE, soluble receptor for advanced glycation end products.

ference, elevated TG, and decreased HDL. These results are similar to those reported in adults where, in addition to MetS [33], they suggested dAGEs participation in the development of insulin resistance [34]. It should be noted that these MetS components, insulin and HOMA, are significantly increased in the OB group.

Our study confirms that sRAGE is lower in adolescents with OB. It has been postulated that a higher AGE flux can decrease sRAGE levels; on the other hand, it is known that sRAGE has other ligands besides AGEs that could be decreasing it, so the results of sRAGE could be reflecting greater binding of AGEs and the other ligands, probably the higher consumption of AGEs in the diet added to the endogenous formation of AGEs favors the greater use of sRAGE [35].

Our results are in agreement with de Giorgis et al. [16] and D'Adamo et al. [17] who evaluated obese prepubertal children and found lower levels of sRAGE compared 
with NW and with Chih-Tsueng He et al. [36] who demonstrate that BMI was an independent predictive factor for plasma sRAGE levels in adolescents; however, they did not found an association with HOMA-IR. Another study [37] also found that adolescents with OB had reduced sRAGE and greater HOMA-IR, which are associated with cardiovascular risk. The results suggested that sRAGE levels may reflect preclinical altered metabolism that could later lead to vascular complications and diabetes [37]. It has been posited that IR may play a role in downregulation of sRAGE [38], which is also supported by our data. Therefore, IR would come first, an excess of glucose and its metabolites, mainly MG would increase cellular AGE formation and spill-over of partially digested modified AGE peptides and free adducts to the bloodstream.

To ascertain that early modification in vascular damage may be linked to the AGE/RAGE axis, we also evaluated FMD and arterial stiffness, which define endothelial dysfunction and impaired structure of the vessels, respectively, in the first phase of the atherosclerotic process [8, 39]. Further, we also evaluated the AI that has been used as a cardiovascular risk predictor based on several epidemiological studies [40, 41].

Indeed, AGE/RAGE axis parameters in the group with $\mathrm{OB}$ are associated with vascular damage even in adolescents, which is another novelty of our results. We found a negative correlation between sRAGE and FMD and a positive correlation with arterial stiffness in the group with $\mathrm{OB}$; these results are in agreement with Villegas et al. [42], who studied adults with newly diagnosed diabetes; other authors like Kajikawa et al. [43] found that in adults, endothelial dysfunction is positively associated with sRAGE and negatively associated with serum levels of AGEs. However, after adjustment for age, sex, and BMI, among other confounder variables, neither AGEs nor sRAGE correlated with FMD, while Fujisawa et al. [15], in a cohort study, found a higher risk for cardiovascular disease when sRAGE was higher. There is no consensus about these results, probably reflecting chronic [44] versus acute changes [42] and the clinical significance of sRAGE as a biomarker of cardiovascular risk that might differ considerably depending on the subjects' background, presence or absence of diabetes, and age. Although the reports in the literature are controversial, most of the literature supports that sRAGE is associated with greater cardiovascular risk. In agreement with our results, a study in adults demonstrated that serum sRAGE level was independently correlated with a marker of central aortic stiffness and suggested a potential role of RAGE

AGE-sRAGE in Adolescents with OB in the pathogenesis of aortic stiffness [45]. CML and total AGEs are positively correlated with the AI, which have been considered as cardiovascular risk factors in adults [24].

Our results and other studies demonstrate that $\mathrm{OB}$ is associated with low levels of sRAGE [17] and that an impairment of the RAGE system represents an important risk factor for the development of atherosclerosis [12]. There is evolving evidence that clinical indicators of atherosclerosis such as intima-media thickness, arterial stiffness, and endothelial dysfunction are altered in children with $\mathrm{OB}$, although the strength of the associations and mechanisms by which these effects are mediated have not been fully elucidated [8]. However, more studies are warranted to determine the mechanisms involved in the associations between AGE/RAGE components and markers of vascular damage.

This study has some limitations. The sample size, although with sufficient power, is relatively small, yet it showed clear differences in sRAGEs and FMD. A more complete picture of the changes found in the AGE/RAGE axis can be obtained with future studies evaluating MG hydroimidazolone- 1 and the different forms of sRAGEs: esRAGE and their ratios, and prospective studies are required to clarify the role of sRAGE in the genesis and progression of vascular damage.

\section{Conclusion}

The group of adolescents with $\mathrm{OB}$ showed higher cardiometabolic risk as shown by higher TG, AI, HOMA-IR, and lower sRAGE and FMD.

Moreover, we also show that impaired endothelial function is already present in adolescents with $\mathrm{OB}$ and that sRAGE is associated with FMD and arterial stiffness and CML and total AGEs are associated with AI.

\section{Acknowledgments}

The authors thank all the participants who volunteered for this study such as colleagues who provided technical support.

\section{Statement of Ethics}

This study was approved by the institutional Ethical Committee at the University of Guanajuato (CIBIUG-P-28-2015). Both adolescents and their parents or tutors signed an informed consent form. 


\section{Disclosure Statement}

The authors declare that there is no conflict of interests regarding this publication.

\section{Funding Sources}

This work was supported by Direction of Research and Postgraduate Support, University of Guanajuato (Project 011/2015) and Touro University-California (069).

\section{Author Contributions}

R.R.-M., C.L.-C., S.S.-M., A.G., and M.E.G.-S.: participated in study design, data collection, data analysis, literature search, generation of figures, and writing of the manuscript. R.R.-M., A.G.-O., R.C., Y.B., and A.G.: carried out experiments. All authors were involved in data interpretation, writing the manuscript, and had final approval of the submitted and published versions.

\section{References}

1 PAHO, WHO. Plan of action for the prevention of obesity in children and adolescents 2014; 19:16-20.

2 Ho M, Benitez-Aguirre PZ, Donaghue KC, Mitchell P, Baur LA, Jenkins AJ, et al. Arterial elasticity in obese adolescents with clinical features of insulin resistance. Diab Vasc Dis Res. 2015 Jan;12(1):62-9.

3 Cavalcante JL, Lima JA, Redheuil A, Al-Mallah MH. Aortic stiffness: current understanding and future directions. J Am Coll Cardiol. 2011 Apr;57(14):1511-22.

4 Widlansky ME, Gokce N, Keaney JF Jr, Vita JA. The clinical implications of endothelial dysfunction. J Am Coll Cardiol. 2003 Oct; 42(7):1149-60.

5 Ozcetin M, Celikyay ZR, Celik A, Yilmaz R, Yerli Y, Erkorkmaz U. The importance of carotid artery stiffness and increased intimamedia thickness in obese children. S Afr Med J. 2012 Mar;102(5):295-9.

6 Tryggestad JB, Thompson DM, Copeland KC, Short KR. Obese children have higher arterial elasticity without a difference in endothelial function: the role of body composition. Obesity (Silver Spring). 2012 Jan;20(1):16571.

7 Lurbe E, Torro I, Garcia-Vicent C, Alvarez J, Fernández-Fornoso JA, Redon J. Blood pressure and obesity exert independent influences on pulse wave velocity in youth. Hypertension. 2012 Aug;60(2):550-5.

8 Cote AT, Harris KC, Panagiotopoulos C, Sandor GG, Devlin AM. Childhood obesity and cardiovascular dysfunction. J Am Coll Cardiol. 2013 Oct;62(15):1309-19.

9 Rodríguez-Morán M, Guerrero-Romero F, Aradillas-García C, Bermudez-Peña C, Simental-Mendia LE, Vargas Morales JM, et al. Atherogenic indices and prehypertension in obese and non-obese children. Diab Vasc Dis Res. 2013 Jan;10(1):17-24.

10 Luévano-Contreras C, Gómez-Ojeda A, Macías-Cervantes MH, Garay-Sevilla ME. Dietary advanced glycation end products and cardiometabolic risk. Curr Diab Rep. 2017 Aug;17(8):63.

11 Uribarri J, Woodruff S, Goodman S, Cai W, Chen X, Pyzik R, et al. Advanced glycation end products in foods and a practical guide to their reduction in the diet. J Am Diet Assoc. 2010 Jun;110(6):911-16.e12.

12 Koyama H, Nishizawa Y. AGEs/RAGE in CKD: irreversible metabolic memory road toward CVD? Eur J Clin Invest. 2010 Jul;40(7): 623-35.

13 Uribarri J, del Castillo MD, de la Maza MP, Filip R, Gugliucci A, Luevano-Contreras C, et al. Dietary advanced glycation end products and their role in health and disease. Adv Nutr. 2015 Jul;6(4):461-73.

14 Lindsey JB, Cipollone F, Abdullah SM, McGuire DK. Receptor for advanced glycation end-products (RAGE) and soluble RAGE (sRAGE): cardiovascular implications. Diab Vasc Dis Res. 2009 Jan;6(1):7-14.

15 Fujisawa K, Katakami N, Kaneto H, Naka T, Takahara M, Sakamoto F, et al. Circulating soluble RAGE as a predictive biomarker of cardiovascular event risk in patients with type 2 diabetes. Atherosclerosis. 2013 Apr;227(2):425-8.

16 de Giorgis T, D’Adamo E, Giannini C, Chiavaroli V, Scarinci A, Verrotti A, et al. Could receptors for advanced glycation end products be considered cardiovascular risk markers in obese children? Antioxid Redox Signal. 2012 Jul;17(2):187-91.

17 D’Adamo E, Giannini C, Chiavaroli V, de Giorgis T, Verrotti A, Chiarelli F, et al. What is the significance of soluble and endogenous secretory receptor for advanced glycation end products in liver steatosis in obese prepubertal children? Antioxid Redox Signal. 2011 Mar;14(6):1167-72.

18 Strong JP, Malcom GT, McMahan CA, Tracy RE, Newman WP 3rd, Herderick EE, et al. Prevalence and extent of atherosclerosis in adolescents and young adults: implications for prevention from the Pathobiological Determinants of Atherosclerosis in Youth Study. JAMA. 1999 Feb;281(8):727-35.

19 Cole TJ, Bellizzi MC, Flegal KM, Dietz WH. Establishing a standard definition for child overweight and obesity worldwide: international survey. BMJ. 2000 May;320(7244): 1240-3.

20 Arrebola-Moreno AL, Laclaustra M, Kaski JC. Noninvasive assessment of endothelial function in clinical practice. Rev Esp Cardiol (Engl Ed). 2012 Jan;65(1):80-90.

21 Mackenzie IS, Wilkinson IB, Cockcroft JR. Assessment of arterial stiffness in clinical practice. QJM. 2002 Feb;95(2):67-74.

22 Aradillas-García C, Rodríguez-Morán M, Garay-Sevilla ME, Malacara JM, Rascon-Pacheco RA, Guerrero-Romero F. Distribution of the homeostasis model assessment of insulin resistance in Mexican children and adolescents. Eur J Endocrinol. 2012 Feb;166(2):3016.

23 Mitsuhashi T, Vlassara H, Founds HW, Li YM. Standardizing the immunological measurement of advanced glycation endproducts using normal human serum. J Immunol Methods. 1997 Aug;207(1):79-88.

24 Gugliucci A, Bendayan M. Renal fate of circulating advanced glycated end products (AGE): evidence for reabsorption and catabolism of AGE-peptides by renal proximal tubular cells. Diabetologia. 1996 Feb;39(2):149-60.

25 Sebeková K, Somoza V, Jarcusková M, Heidland A, Podracká L. Plasma advanced glycation end products are decreased in obese children compared with lean controls. Int J Pediatr Obes. 2009;4(2):112-8.

26 Accacha S, Rosenfeld W, Jacobson A, Michel L, Schnurr FJ, Shelov S, et al. Plasma advanced glycation end products (AGEs), receptors for AGEs and their correlation with inflammatory markers in middle school-age children. Horm Res Paediatr. 2013;80(5):318-27.

27 Garay-Sevilla ME, Torres-Graciano S, Villegas-Rodríguez $\mathrm{ME}$, Rivera-Cisneros $\mathrm{AE}$, Wrobel K, Uribarri J. Advanced glycation end products and their receptors did not show any association with body mass parameters in metabolically healthy adolescents. Acta Paediatr. 2018 Dec;107(12):2146-51.

28 Masania J, Malczewska-Malec M, Razny U, Goralska J, Zdzienicka A, Kiec-Wilk B, et al. Dicarbonyl stress in clinical obesity. Glycoconj J. 2016 Aug;33(4):581-9.

29 Nishimura R, Kanda A, Sano H, Matsudaira T, Miyashita Y, Morimoto A, et al. Glycated albumin is low in obese, non-diabetic children. Diabetes Res Clin Pract. 2006 Mar; $71(3): 334-8$ 
30 Semba RD, Arab L, Sun K, Nicklett EJ, Ferrucci L. Fat mass is inversely associated with serum carboxymethyl-lysine, an advanced glycation end product, in adults. J Nutr. 2011 Sep;141(9):1726-30.

31 Schmidt AM, Stern D. Atherosclerosis and diabetes: the RAGE connection. Curr Atheroscler Rep. 2000 Sep;2(5):430-6.

32 Saha A, Poojary P, Chan L, Chauhan K, Nadkarni G, Coca S, et al. Increased odds of metabolic syndrome with consumption of high dietary advanced glycation end products in adolescents. Diabetes Metab. 2017 Oct;43(5): $469-71$.

33 Uribarri J, Cai W, Woodward M, Tripp E, Goldberg L, Pyzik R, et al. Elevated serum advanced glycation endproducts in obese indicate risk for the metabolic syndrome: a link between healthy and unhealthy obesity? J Clin Endocrinol Metab. 2015 May;100(5):1957-66.

34 Vlassara H, Cai W, Goodman S, Pyzik R, Yong A, Chen X, et al. Protection against loss of innate defenses in adulthood by low advanced glycation end products (AGE) intake: role of the antiinflammatory AGE receptor-1. J Clin Endocrinol Metab. 2009 Nov;94(11): 4483-91.

35 Ramasamy R, Yan SF, Schmidt AM. The diverse ligand repertoire of the receptor for advanced glycation endproducts and pathways to the complications of diabetes. Vascul Pharmacol. 2012 Nov-Dec;57(5-6):160-7.

$36 \mathrm{He}$ CT, Lee CH, Hsieh CH, Hsiao FC, Kuo P, $\mathrm{Chu} \mathrm{NF}$, et al. Soluble form of receptor for advanced glycation end products is associated with obesity and metabolic syndrome in adolescents. Int J Endocrinol. 2014;2014:657607.

37 Rowisha M, El-Batch M, El Shikh T, El Melegy $\mathrm{S}$, Aly H. Soluble receptor and gene polymorphism for AGE: relationship with obesity and cardiovascular risks. Pediatr Res. 2016 Jul; 80(1):67-71.

38 Basta G, Sironi AM, Lazzerini G, Del Turco S, Buzzigoli E, Casolaro A, et al. Circulating soluble receptor for advanced glycation end products is inversely associated with glycemic control and S100A12 protein. J Clin Endocrinol Metab. 2006 Nov;91(11):4628-34.

39 Głowińska-Olszewska B, Tołwińska J, Urban M. Relationship between endothelial dysfunction, carotid artery intima media thickness and circulating markers of vascular inflammation in obese hypertensive children and adolescents. J Pediatr Endocrinol Metab. 2007 Oct;20(10):1125-36.

40 Olamoyegun MA, Oluyombo R, Asaolu SO. Evaluation of dyslipidemia, lipid ratios, and atherogenic index as cardiovascular risk factors among semi-urban dwellers in Nigeria. Ann Afr Med. 2016 Oct-Dec;15(4):194-9.
41 Millán J, Pintó X, Muñoz A, Zúñiga M, Rubiés-Prat J, Pallardo LF, et al. Lipoprotein ratios: physiological significance and clinical usefulness in cardiovascular prevention. Vasc Health Risk Manag. 2009;5:757-65.

42 Villegas-Rodríguez ME, Uribarri J, SolorioMeza SE, Fajardo-Araujo ME, Cai W, TorresGraciano S, et al. The AGE-RAGE axis and its relationship to markers of cardiovascular disease in newly diagnosed diabetic patients. PLoS One. 2016 Jul;11(7):e0159175.

43 Kajikawa M, Nakashima A, Fujimura N, Maruhashi T, Iwamoto Y, Iwamoto A, et al. Ratio of serum levels of AGEs to soluble form of RAGE is a predictor of endothelial function. Diabetes Care. 2015 Jan;38(1): 119-25.

44 Chiang KH, Huang PH, Huang SS, Wu TC, Chen JW, Lin SJ. Plasma levels of soluble receptor for advanced glycation end products are associated with endothelial function and predict cardiovascular events in nondiabetic patients. Coron Artery Dis. 2009 Jun;20(4): 267-73.

45 Yoon SJ, Park S, Park C, Chang W, Cho DK, Ko YG, et al. Association of soluble receptor for advanced glycation end-product with increasing central aortic stiffness in hypertensive patients. Coron Artery Dis. 2012 Mar; 23(2):85-90 